NISTIR 88-4032

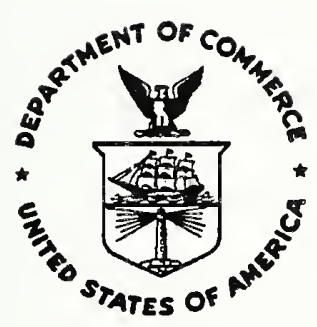

\title{
Assessing the Flammability of Composite Materials
}

\author{
T. Ohlemiller
}

U.S. DEPARTMENT OF COMMERCE

National Institute of Standards and Technology

(Formerly National Bureau of Standards)

National Engineering Laboratory

Center for Fire Research

Gaithersburg, MD 20899

January 1989

Sponsored by:

David Taylor Research Center

United States Navy

Annapolis, MD 



\title{
NISTIR 88-4032
}

\section{Assessing the Flammability of Composite Materials}

T. Ohlemiller

\section{U.S. DEPARTMENT OF COMMERCE}

National Institute of Standards and Technology

(Formerly National Bureau of Standards)

National Engineering Laboratory

Center for Fire Research

Gaithersburg, MD 20899

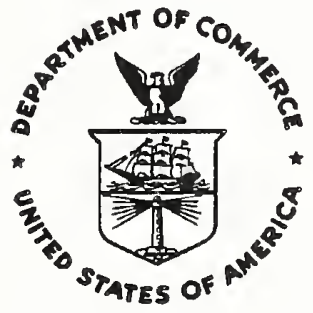

National Bureau of Standards became the National Institute of Standards and Technology on August 23, 1988, when the Omnibus Trade and Competitiveness Act was signed. NIST retains all NBS functions. Its new programs will encourage improved use of technology by U.S. industry.

Sponsored by:

David Taylor Research Center

United States Navy

Annapolis, MD

\author{
U.S. DEPARTMENT OF COMMERCE \\ C. William Verity, Secretary \\ Ernest Ambler, Acting Undersecretary \\ for Technology \\ NATIONAL INSTITUTE OF STANDARDS \\ AND TECHNOLOGY \\ Raymond G. Kammer, Acting Director
}



TABLE OF CONTENTS

\section{Page}

List of Tables . . . . . . . . . . . . . . . . . . . . . . . iv

List of Figures . . . . . . . . . . . . . . . . . . . . . . . . . v

Summary . . . . . . . . . . . . . . . . . . . . . . . 1

1. INTRODUCTION . . . . . . . . . . . . . . . . . . 1

2. FLAMMABILITY TESTS AND ASSOCIATED PARAMETERS . . . . . . . . . . . 3

Ignitability . . . . . . . . . . . . . . . . . . . . 4

Rate Heat of Release . . . . . . . . . . . . . . . 6

Opposed Flow Flame Spread . . . . . . . . . . . . . . 8

Upward Flame Spread . . . . . . . . . . . . . . . 10

3. CONCLUDING REMARKS . . . . . . . . . . . . . . . . . 13

4. REFERENCES ........................ . . . . . . . . . . . . . . . . . 


\section{LIST OF TABLES}

$\underline{\text { Page }}$

Table 1. Characterization of Material Flammability . . . . . . . . . 15

Table 2. Parameters Inferred From Lift Apparatus Data . . . . . . 17 


\section{LIST OF FIGURES}

$\underline{\text { Page }}$

Figure 1. Ignition data for fiberboard correlated by Eqn. (2) . . . . 18

Figure 2. Schematic of Lateral Ignition and Flame Spread

(LIFT) apparatus . . . . . . . . . . . . . . . . 18

Figure 3. Schematic of Cone Calorimeter for measurement

of rate of heat release . . . . . . . . . . . . . . . 19

Figure 4. Dependence of peak rate of heat release on incident

heat flux; candidate materials for aircraft interior

panels .................... . . 19

Figure 5. Schematic of apparatus for measuring the heat flux

from a flame to the surface of a material above the

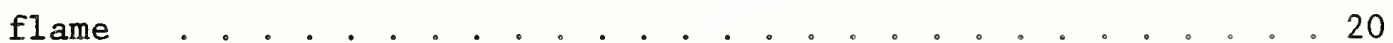



A comprehensive approach to properly characterizing the flammability of composite materials is outlined. Laboratory-scale tests are described which provide measures of material ignitability, flame spread rate and heat release rate. Rather than expressing these measures as arbitrary indices, they are interpreted in terms of models of the controlling phenomena designed to provide information that can be generalized to full-scale contexts, particularly compartment fires.

\section{1) INTRODUCTION}

Composite materials of interest to the Navy for structural or protective use aboard ships typically consist of two phases: high strength, usually inorganic filaments, possibly woven together, and a polymeric matrix which permeates the filaments. The filaments provide nearly all of the mechanical strength of the composite while the polymer serves to protect and bond the filaments, preventing delamination. Depending on the application, a single layer of such a composite may be used (possibly having many plies) or such layers may be used to sandwich other materials such as a honeycomb to make a single structural unit.

While such composites can offer marked advantages over metals in mechanical properties and weight savings, they are subject to a significant new concern: under some circumstances the polymeric binder, being organic in nature, will burn. Thus a composite may contribute to the spread of a fire away from an ignition source by propagating a flame along its own surface or by adding fuel gases to an adjacent fire in another material.

Since these composite materials are frequently expensive to manufacture, it is important to be able to address this flammability issue on small scale samples and yet obtain information that pertains, in a well-defined way, to full-scale applications of interest. For many years flammability has been assessed in a variety of small scale tests, sanctioned by ASTM and other organizations, which seek to mimic some aspect of a real hazard scenario and then to assign a performance index to the sample. Examples of such tests include the ASTM E-84 tunnel test for surface flammability, the ASTM E-162 radiant panel test for downward flame spread and the Limiting Oxygen Index test. These types of tests can provide useful relative measures of the behavior of materials in a fixed set of circumstances but they provide little in the way of quantitative insights or guidelines as to how a material will behave when the conditions are changed. This same drawback applies as well to full-scale testing, in addition to its high cost. While direct testing at full-scale certainly 
avoids the sometimes tenuous relation between small and large scale behavior, one cannot encompass all possible scenarios in such testing.

In view of this, it is vital that one seek an approach that holds the promise of greater generality. In the approach advocated here, the flammability of a material is broken down into its component elements - - ignition, heat release rate and flame spread rate. These are measured for bench-scale segments of the material in the form of actual usage. This last means that the organic composite is faced and/or backed with whatever other materials normally accompany its usage, at least within a thickness relevant to the flow of heat in the sample, usually about 1 or 2 centimeters. Ignitability measures the ease with which a flame can be initiated on the material by a heat source, here taken to be radiative in nature. Rate of heat release measures the output of heat produced by a unit area of the sample assembly due to flaming on its exposed surface. Flame spread rate measures the speed with which a flame can spread over the exposed surface of a sample assembly. This rate can be markedly different in different directions due to the effects of buoyancy on the ability of the flames to heat adjacent elements of the sample. An added complication with all three of these elements of flammability is that they potentially may vary with the physical size of the sample (lateral extent and thickness), degree of air access to the flames, ambient oxygen level and the presence of an added external flux (such as from another burning object). These additional factors can become important when a material is burning in the context of a compartment.

Dealing with these complexities in a manner which allows a flexible predictive capability for a wide range of conditions requires two levels of models of the phenomena involved coupled with a series of measurements which provide quantitative values for parameters in these models. This is the approach taken here. The first level of predictive model describes each flammability element individually, with allowance for possible influences from external heat fluxes. These models, for ignition, rate of heat release and flame spread rate, are necessarily simplified. This is inevitable, both because not all of the phenomena encountered with all materials can be quantified and because the first level models must be tractable within the context of the second level of models which focus on predicting the fire behavior of an entire compartment. The simplified first level models contain certain parameters which are best derived from experiments; for economy and tractability these are bench-scale experiments. Once a material has been characterized in these tests, one can use the first level models to predict its behavior on larger scales. To predict its behavior in the context of a compartment fire calls for incorporating these empirically-fitted, first level descriptions of the flammability of the material into a compartment fire model which keeps track of the additional factors and their influence on the behavior of the material. Compartment fire models are a subject of active research and they have reached a substantial degree of sophistication; the reader is referred to Reference 1 for a discussion of this subject. The principal focus here is on the nature of the measurements needed to implement the first level models of the individual aspects of flammability. 
In summary, the objective here is to define a set of laboratory-scale tests and parameters derived from them; these parameters can then be employed in simplified models of flammability phenomena to make accurate predictions of full-scale fire behavior in a variety of end use configurations. The laboratory-scale tests will thus become a reliable means for screening new materials with regard to flammability hazards.

\section{2) Flammability Tests and Associated Parameters}

Three principal aspects of flammability were noted above - ignition, heat release rate and flame spread. More than three types of tests are required to fully characterize these, as shown in Table 1. The principal area of test proliferation is upward flame spread, which will be discussed last.

It should be noted that all of the tests summarized in Table 1 are focused on flat, vertically-oriented surfaces. Because of the need to probe in-depth into flammability phenomena which may change with scale, it is necessary to focus on one physical situation at a time. Composite materials are frequently employed as vertical panels in structural or non-structural roles so a vertical flat surface is a logical starting point. This choice is abetted by the fact that the burning of vertical surfaces is an area where significant research advances are currently being made. As the state of the art for other configurations and orientations advances, they too can become the focus of an in-depth effort to relate small scale test results to full-scale fire behavior; horizontal surfaces are the next logical area of interest. Some of the test methods in Table 1 , most notably those done in the Cone Calorimeter and the Modified Cone Calorimeter, are readily applied to horizontal surfaces.

It is pertinent to reiterate a point made earlier. The sample to be characterized by the tests in Table 1 should consist of whatever number of layers of diverse materials one intends to use in an actual application, at least to a depth that will influence the flow of heat and hence the thermal response of the exposed surface. This depth of heat penetration depends on the length of the heat exposure and the thermal diffusivity of the composite as follows

$$
l=\sqrt{\alpha t}
$$

where $\ell$ is the depth of heat penetration, $\alpha$ is the effective thermal diffusivity of the degrading composite and $t$ is the total time of heat exposure. Since the effective thermal diffusivity of the thermally degrading composite might not be precisely known, it is best to err on the safe side and include more rather than fewer layers of the end-use configuration.

The discussion below expands on the information summarized in Table 1 . Before considering the individua]. tests, however, it is useful to envision the sort of scenarios which these tests methods seek to quantify. The focus is on vertically-oriented flat surfaces composed, at least in part, of composite materials; this could be a compartment wall, the side of a container or 
machinery cover, etc. It is assumed that some source of intense heat is brought to bear on some part of this surface, possibly as a result of a flammable liquid fire, for example. This local heating will raise the surface temperature of the composite assembly to a point where its organic components will begin to degrade rapidly and partially gasify. As soon as the mixture of gases and air above the composite surface is within the flammable limit, it can ignite if it is in contact with a sufficiently hot material. It is assumed here that rapid ignition is the worst case and so, in performing ignition tests, a pilot flame is provided that ignites the gas mixture at the earliest possible time.

Once a local portion of the composite assembly begins to burn, it begins to release heat at a rate determined by the heat flux from its own flame and from the separate fire which ignited it. This rate of heat release is a strong determinant of the length of flame extending upward from the burning portion of the composite. Buoyancy drives this flame and its attendant hot gas plume upward thus assuring that material above the flaming region will be the most effectively heated. The result is that, in effect, successive portions of the material above the originally ignited region are themselves ignited, as a consequence of the external heat flux and the flame heat flux combined. This is vertical flame spread; the large heat contribution from the upward-swept flame makes it potentially the most rapid direction of spread. At the same time, however, the flame supplements the heating of surface elements below and to the sides of the originally ignited region. The buoyant flow opposes spread in these directions altering the mechanics of this mode of spread and rendering it generally somewhat slower than upward spread. If the flaming region continues to extend in all of these directions, the combustion of the composite material could soon dominate over the original igniter fire. Extension of the fire is not assured. This depends, among other things, on the rate of heat release from each element of burning surface and on the duration of that burning.

If this fire does continue to grow bigger, it is likely soon to be influenced by other aspects of its surroundings. If the fire is in a compartment, the hot gases and soot from the fire plume will accumulate below the ceiling forming a new source of radiant heat to the flaming vertical surface. If the compartment is closed, oxygen depletion will slow the flames, possibly causing the accumulation of flammable gases in the upper layer below the ceiling. These compartment effects are not directly considered here although allowance for their impact is implicit in some of the model equations below.

With this type of scenario in mind, we can now examine how the following tests can help to quantify the flammability behavior that it encompasses.

Ignitability. The principle measure of ignitability is the time delay between the application of a heat flux to a sample surface and the achievement of flaming ignition. As noted above, the delay time is shortest and the hazard thus greatest for the case of piloted ignition. The time delay is then dictated by the need to get the temperature of the sample surface to the point where it degrades and gasifies rapidly. Clearly, the delay will be less if the incident heat flux is greater. Quintiere, et al [2] have shown that, for 
flat vertical surfaces heated by a constant flux, the heat flux and the ignition delay time can be related by the following semi-empirical expression

$$
\left(q_{0, i s} / q_{\theta}\right)=b \sqrt{t}
$$

Here $q_{\theta}$ is the external heat flux and $t$ is the ignition delay time. The quantity $\mathrm{q}_{0, i g}$ is the minimum heat flux necessary to cause ignition. This is the external flux which will just get the sample surface temperature to the point where it will gasify and produce a flame; heat losses, present in all cases, prevent the surface from reaching this minimum temperature for ignition if the external flux is less than $q_{0, i g}$. The quantity $b$ is an empirical coefficient to be obtained from bench-scale measurements of ignition delay time as a function of incident heat flux; it implicitly contains a useful parameter, as will be discussed below. Figure 1, taken from Reference 13, shows ignition data for a char-forming material, wood-based fiberboard, correlated in accord with Eqn. (2).

Implicit in the above equation are certain assumptions. First, it is assumed that the heat flow is one-dimensional, $i$. e., heat only flows normal to the sample surface. Second, it is assumed that the sample is thermally thick, i. e., that the heat from the external source does not penetrate to the back surface of the sample; this issue was addressed above in relation to Eqn. (1). There is also a simplified description of the ignition process implicit in Eqn. (2). It is assumed that reaching a unique sample surface temperature is all that is required for ignition in all cases. These assumptions are quite reasonable for a wide variety of circumstances but one must be aware that they can sometimes fail to hold true. A more subtle assumption implicit in Eqn.

(2) is that the gases evolved from the heated region on the sample flow out in a one-dimensional manner, establishing a flame that sustains itself by a similar, one-dimensional flow of gases from increasing depths in the sample. In some heat flux ranges some composite structures do not behave this way. Instead, the gas flow from the sample interior can more readily escape by some path that takes it to the lateral edge of the sample. Thus the edges of composite assemblies may differ substantially in their flammability behavior from areas well away from edges; this is an area of research for the near future. In the meantime, as noted in Table 1, one can apply the flammability assessment approach outlined here since it is certainly pertinent for areas away from sample edges. Where edge effects dominate, interpretation of the results requires further study. Indeed, there may prove to be two ignition modes pertinent to some composite materials - that of the face and that of the edges.

As noted in Table 1 , one can obtain ignition delay data on composite materials in either of two apparatuses, the Lateral Ignition and Flame Spread (LIFT) apparatus or the Cone Calorimeter. Ignition delay data from the Cone Calorimeter are usually obtained at the relatively few heat flux levels at which one wants to assess the rate of heat release (though one could use more levels, if desired). The LIFT apparatus is typically utilized over a greater range of incident heat fluxes, particularly in seeking to evaluate the minimum flux for ignition. The Cone ignition data thus can be viewed as a cross-check on the LIFT data. 
Figure 2 is a schematic of the LIFT apparatus. The external flux is seen to come from a gas-fired radiant panel which makes an angle of about $15^{\circ}$ with the front surface of the test sample. This angle causes a spatially varying flux on the long samples used for flame spread measurements. The peak flux from the panel is adjusted by varying the flow rate of natural gas which raises or lowers the panel temperature. The flux distribution on the sample surface is always similar regardless of the panel temperature, $i$. e., the fractional change relative to the peak flux is always the same at any given point along the sample surface. For ignition test, the sample occupies only the nearly uniform flux region around the peak flux. An acetylene/air flame just above the top edge of the sample is the pilot. The panel is brought to a steady state at the desired flux level and the sample in its holder is quickly inserted into place. The ignition delay is measured with a stopwatch. This procedure is repeated with about a dozen separate samples to fully characterize the heat flux dependence and the minimum flux for ignition.

The value of the coefficient $b$ in Eqn. (2) is obtained by fitting the equation to the data. This coefficient can be shown to be related to the thermal inertia of the sample assembly [2] and so its value can be derived from $b$. Thermal inertia, defined here as the product of thermal conductivity, density and specific heat, denoted as $(k \rho C)$, is the unique combination of material properties which measures the amount of heat it takes to raise the surface temperature of a material by any given amount in a given time as a result of surface heating. The value obtained from these ignition experiments is an effective value averaged over the temperature range up to ignition and averaged over any chemical and physical changes which the sample undergoes in this process. From the minimum flux for ignition one can calculate the minimum surface temperature for ignition; again this is an effective value. Both the thermal inertia and the minimum surface temperature for ignition are parameters used in flame spread models as discussed below. The ignition delay data themselves are approximately applicable to larger scale ignition situations for a flat vertical surface of the same composition. Piloted ignition delay appears to be only weakly dependent on scale [3].

Rate of Heat Release. This aspect of flammability is measured by oxygen consumption calorimetry. This utilizes the fact that the heat of combustion of most materials is nearly constant when it is referenced to the mass of oxygen consumed. Oxygen consumption is more readily measured than direct heat evolution.

The rate of heat release is proportional to the rate of mass loss from a material which, in turn, depends on the heat flux to the surface of the material. Since, in a fire, this flux comes both from the flame on the material and any external sources (other burning items, the hot upper smoke layer accumulating in a compartment, etc.), rate of heat release must be measured as a function of added heat flux. The Cone Calorimeter utilizes a cone-shaped electric resistance heater to provide various fixed radiant flux levels; see Figure 3. 
At any given constant levels of heat flux and ambient oxygen, the rate of heat release from any but the simplest materials is a somewhat complex function of time. It typically consists of an initial peak followed by a decay reflecting the build-up of either char or inert material on the sample surface. Finally, if the material continues to burn and the thermal wave in the sample assembly reaches the back surface, there will be a second peak before the flame dies out. By dividing the instantaneous heat release rate by the mass loss rate, one can determine the instantaneous heat of combustion per mass of material gasified; in general this is not a constant for char-forming materials though it is frequently assumed to be so. It is needed for some formulations of flame spread models.

The heat release rate data has both the overall time dependence just noted plus a moderate amount of noise-like variability superimposed upon it. Thus it is frequently time-averaged to varying extents to simplify the discernment of trends. Even the peak heat release rate (initial peak) reported is frequently the average over some short time interval that includes the instantaneous peak. It is this "time-averaged" peak that one can examine for sensitivity to variations in external flux. This sensitivity can differ substantially from one material to another with the result that a rankordering of two materials on the basis of heat release rate can invert depending on the incident flux level involved. Figure 4, taken from Reference 11 , illustrates this type of behavior for a series of materials of potential use as aircraft interior panels. The composites shown there are identified by the composition of the facing material; in all cases, these facings were used to sandwich a Nomex honeycomb. Data for three non-composites are also shown.

Some attempts have been made to find correlations between Cone Calorimeter measurements of peak heat release rate and aspects of compartment fires involving the same materials. Babrauskas and Wickstrom [4] report some success with upholstered furniture (correlation of full-scale peak heat release rate from the Cone result) and with wall lining materials (prediction of heat release rate vs. time for the early stages of a fire in a lined compartment from Cone Calorimeter data on heat release rate and ignition delay time). Quintiere [5] showed that a similar correlation between Cone data and maximum upper layer temperature in a lined compartment (a measure of peak full-scale heat release rate) was quite poor if one did not account for differing rates of flame spread as well as heat release rate per unit area of fuel. Wickstrom and Goransson [6] (whose work is the source for the wall lining results quoted in Reference 4) took this spread factor into account by fitting an empirical function to measurements of the extent of flame spread as a function of time in the full-scale compartment. This empirical function was made to depend only on the ignition delay time of the material at an arbitrarily chosen heat flux of $25 \mathrm{~kW} / \mathrm{m}^{2}$. Some of the approximations in this approach are rough but it shows some promise for first-cut estimates of early compartment heat release rate behavior.

Cone calorimeter data are difficult to use directly in the context of fire spread models. This is a consequence of the fact that the heat release data are obtained at constant external radiant flux levels whereas what is needed for any model is the heat release for an arbitrarily time-dependent net flux through the sample surface. This is an area of current research. 
The Modified Cone Calorimeter is the same basic device as shown in Fig. 3 except that the sample region is enclosed so as to permit ambient atmosphere control. Thus one can ascertain the effects of lowered oxygen levels on the heat flux dependent rate of heat release and on the average heat of combustion. In so doing, one begins to get a measure of the decreases that may occur in these quantities as a result of oxygen depletion in a compartment fire. By lowering the oxygen level in the purge gas to zero, one can suppress flaming and measure the mass loss rate due to fixed levels of external radiation alone. This allows one to infer the average heat of gasification of the material. Heat of gasification is the total heat that must be input to unit mass of a material to first raise its temperature to the point where it can gasify and then to convert it from solid to gas. ${ }^{1}$ In general this is not a constant for char-forming materials. However, it is useful, for a first-cut estimate of the rate of gasification of a material in a fire situation, to utilize an average value for this heat of gasification. Mitler [7] has recently shown how one can utilize the heat of gasification approach (plus other inputs) to make a good prediction of the behavior of a non-charring material burning in a compartment; this algorithm is even able to account for the response of the material to the radiant feedback (input from measurements) from the compartment and the depletion of oxygen (input from measurements) in the upper layer. A similar test of this approach for a charring material is lacking at present.

Opposed Flow Flame Spread. This refers, in general, to any situation in which a flame is spreading in a direction opposite to a flow of air. The cases of interest here include lateral flame spread across a wall and downward flame spread on a wall. The air flow is induced by the buoyancy of the flames; it sweeps the flames back away from the direction of spread, minimizing their effectiveness in preheating the adjacent material. This is the reason that this type of spread is generally slower than upward flame spread. Quintiere et al [8] have shown that for at least one char-forming material (particle board), the lateral and downward flame spread rates are approximately equal as a function of external flux; thus it appears that only one of these two modes needs to be investigated for a material unless a high degree of precision is needed. Flame spread across a flat horizontal surface also falls into this opposed flow category and follows a similar mechanism; Atreya, et al [12] have shown that, at least for wood, horizontal flame spread is equal in speed to lateral spread.

The opposed flow flame spread rate can be described by the following semiempirical expression [2]:

$$
V_{p}=\Phi /(k \rho C)\left(T_{i g}-T_{s}\right)^{2}
$$

\footnotetext{
${ }^{1}$ An alternative definition is the ratio of the net heat flux into the sample surface divided by its rate of gasification.
} 
Here $V_{p}$ is the flame spread rate, $\Phi$ is a parameter which is a measure of the heat flow from the flame to the solid, $(k \rho C)$ is the effective thermal inertia of the sample, as explained above in relation to Eqn. (2), $\mathrm{T}_{\mathrm{ig}_{\mathrm{g}}}$ is the minimum temperature of ignition of the sample, also explained above, and $T_{s}$ is the temperature of the sample ahead of any flame heating. This temperature could be elevated as a result of an external radiant flux having preheated the material before the flame arrives. Such preheating is usually necessary for char-forming materials if a flame is to spread at all but it is frequently present in many realistic fire scenarios; such materials thus have a critical pre-heat temperature for opposed flow flame spread. The quantities (kpC) and $\mathrm{T}_{\mathrm{i} \&}$ are derived from the ignitability characterization, as described above. Only the quantity $\Phi$ needs to be determined in order for one to be able to describe the lateral or downward flame spread behavior of a material by means of Eqn. (3).

The above equation implicitly contains several assumptions. First, it is assumed that the geometry of the sample does not change during the flame spread process. Even if the fixed geometry assumption fails, thereby altering the thermal properties of the sample, use of the empirically determined value for $(k \rho C)$ should largely compensate for this. Extreme sample geometry changes will probably cause the model to be inapplicable, however. Second, it is assumed that the value of $T_{18}$ is the same in ignition and in flame spread; this is a corollary of the common picture of flame spread as a continual series of ignitions moving across the sample surface. Third, it is assumed that there is a one-dimensional flow of heat into and gas out of the sample. The heat flow at the flame front is actually two-dimensional; the empirical factor $\Phi$ can be viewed as compensating for this. The assumption of onedimensional gas flow was discussed above in connection with Eqn. (2); it was noted that this assumption fails for some composite materials in some flux ranges. Flame spread may then occur preferentially at the sample edges if the gases emerge there. This issue will be subjected to close scrutiny in the near future. Again, one can anticipate that some composites will exhibit two distinct modes of lateral flame spread, face and edge.

The LIFT apparatus (Fig. 2), described above for the characterization of ignitability, is also used to characterize lateral flame spread behavior. The short ignition sample is replaced by a full length sample $(79.4 \mathrm{~cm})$. This means that there is an incident heat flux gradient along the length of the sample and this allows one to characterize the flux dependence of the lateral flame spread rate in each test. Also one obtains the minimum incident heat flux for continued flame spread.

As Eqn. (3) indicates, pre-heating the sample should increase the rate of flame spread. Flame spread at any given heat flux is thus not unique; it depends on the extent of pre-heating. The worst case (with most materials ${ }^{2}$ )

2 If a composite has a thin surface layer of relatively flammable material over a core of less flammable material, waiting until the equilibrium surface temperature is reached may result in this surface layer being gasified or charred before flame spread is initiated. The flame spread response seen 
is achieved with pre-heating to the point where the surface temperature is in equilibrium with the local incident flux; at this temperature the surface is losing heat by convection and radiation at the same rate it is arriving. The time necessary to reach this equilibrium is dependent on the value of $(k \rho C)$ for the material; this time is inferred from the ignition data.

The usual way of running the LIFT apparatus is to adjust the radiant panel so that its peak heat flux is slightly above the minimum flux for ignition then insert the sample and wait for a pre-heat time equal to the inferred equilibrium time. A pilot flame is then introduced in the highest flux region, igniting it. The subsequent spread of the flame onto the sample region preheated by progressively lower fluxes is followed visually and by video camexa until the flame stops, having reached the locale on the surface where the minimum flux for spread is incident. This procedure is repeated for three to four identical samples to establish the reproducibility of the behavior and the inferred parameters. As Table 1 indicates, those parameters include the factor $\Phi$ in Eqn. (3) as well as the minimum surface temperature at ignition; this temperature is also determined separately from the ignitability data. The relative agreement of the two values is a measure of the degree to which the material behaves in accords with the model assumptions.

Table 2, taken from Reference 11, shows parameters inferred from LIFT apparatus data for the same materials as in Fig. 4. Two symbols there not previously defined are $q_{0, s}$, the minimum incident heat flux for lateral flame spread and $T_{s},_{m i n}$, the minimum material temperature for lateral flame spread. Substantial differences exist among the materials. For example, there are differences as great as a factor of three in minimum flux for flame spread and differences up to $200^{\circ} \mathrm{C}$ in ignition temperatures. Note that two materials are shown to fail to yield lateral flame spread. Both were very thin panels ( 0.06 inches). The polycarbonate tended to melt and flow out of the sample holder; the ULTEM charred extensively and may have been largely degraded in the pre-heat interval. Thus, a shorter pre-heat time or a thicker sample might give different behavior.

Upward Flame Spread. As noted above, upward flame spread is qualitatively different from opposed flow spread because buoyancy sweeps the plume of flame and hot gases upward, allowing it to heat an extended area of the fuel above the region that is actually burning. This extensive pre-heating allows faster upward spread. This mode of flame spread is the least well-characterized by modelling. Quintiere [2] has shown that, with certain simplifying assumptions, the rate of upward flamespread on a material can be expressed by the following equation.

$$
V_{p}=4\left(q_{f}\right)^{2}\left(x_{f}-x_{p}\right) / \pi(k \cdot \rho C)\left(T_{1 g}-T_{s}\right)^{2}
$$

then would be that of the core. The faster flame spread behavior of the thin surface can only be seen by waiting less than the time necessary to reach surface temperature equilibrium. 
Here $V_{p}$ is the upward flame spread velocity, $q_{f}$ is the average heat flux from the flame to the sample surface in the region which is not yet gasifying actively but is being contacted by the visible flame; $x_{f}$ is the distance from the bottom of the fuel to the tip of the visible flame; $x_{p}$ is the distance from the bottom of the fuel to the top of the actively gasifying region. Thus the quantity $\left(x_{f}-x_{p}\right)$ is the distance above the actively burning region of the vertical sample surface which is being most intensely heated by the flame. It is essentially equal to the flame length when that length is measured relative to the upward edge of the burning front. The quantities ( $k \rho C$ ) and $\mathrm{T}_{18}$ have the same meaning as above and their values can be assumed to have been determined by the tests described above. The quantity $T_{s}$ is the temperature of the sample surface well above any flame heating; it may be elevated as a result of heating from some other source.

The two quantities that need to be evaluated before one can use the above equation are $q_{f}$, the average heat flux from the flame, and $\left(x_{f}-x_{p}\right)$, the flame length. The apparatus shown in Fig. 5 allows one to measure both of these as a function of incident radiant flux, up to fluxes of $50 \mathrm{~kW} / \mathrm{m}^{2}$. The sample is ignited with the pilot flame and when its entire surface is fully involved in flaming the measurements begin; thus the measurements are not on a flame which is actually spreading upward since the flame has spread as far upward as it is allowed to before the measurements begin. The heat flux gages embedded in the surface above the burning sample measure the flux profile from the flames. A video record is used to obtain detailed data on flame height.

The results for char-forming or for composite materials are not as simple as the above model implies, though one can obtain a measure of the values that Eqn. (4) requires. Reference 11 contains extensive data from the apparatus in Fig. 5 on the same materials shown in Table 2 and Fig. 4. These materials tend to undergo a pattern of burning which reaches an early peak (in rate of gasification or heat release rate) followed by a rapid decay and, potentially, extinction before all of the fuel is consumed. As a result, flame height is a time-dependent function and the flame heat flux pattern incident on the surface above the burning material is both space and time-dependent. The averages of these quantities thus cannot fully capture all of their important features. Equation (4) tends to be most applicable to materials whose burning time is long compared to the time that would be required for flame to spread upward a length equal to the flame length. When this condition is not satisfied flame spread may not occur at all, only localized burning followed by extinction. A more precise criterion for the existence of upward spread was given by Saito, et al [9] as follows:

$$
\mathrm{KQm}_{0}\left(t_{\mathrm{b}} / 2 \tau\right)^{\frac{1}{2}}>2 / \sqrt{\pi}
$$

According to the model in the above reference, upward flame spread can only occur if this inequality is satisfied. Here $\mathrm{K}$ is an empirical constant in an experimentally-derived relationship between rate of heat release per unit of sample width and flame height, $Q$ is the heat of combustion per unit mass of 
fuel (assumed constant), $\mathrm{m}_{0}$ is essentially the peak rate of mass loss from the sample surface, $t_{b}$ is the nominal burning time of the sample (Reference 11 explains the empirical procedure for determining this parameter) and $\tau$ is the flame spread time noted above; it is defined as follows:

$$
\tau=(\mathrm{k} \rho \mathrm{C})\left(\left(\mathrm{T}_{1 \mathrm{~g}}-\mathrm{T}_{\mathrm{s}}\right) / \mathrm{q}_{\mathrm{f}}\right\}^{2}
$$

The symbols here have the same meaning as in Eqn. (4). It should be noted that Eqn. (5) implies that the existence of upward spread is favored by an increased rate of heat release per unit width of sample and by an increased burning time for each element of sample area relative to the flame spread time, $\tau$. Note further that both of these factors are enhanced by external radiation. The quantity $\mathrm{m}_{0}$ increases with increased incident radiation flux; the ratio $\left(t_{b} / \tau\right)$ increases both because $\tau$ decreases directly as shown by Eqn. (6) and because $T_{s}$ in Eqn. (6) increases. Thus a material which will not support upward flame spread in a very open environment may do so in a compartment because the enclosure, whose surfaces become increasingly hot, increases the incident heat flux on the surface of the material. In Reference 11 it is shown that only three of the materials in Table 2 (ABS, epoxy fiberglass, epoxy Kevlar) satisfy Eqn. (5) at a flux, $q_{f}$, of $25 \mathrm{~kW} / \mathrm{cm}^{2}$; the others require higher (undetermined) fluxes for sustained upward flame spread.

Equations (4) through (6) are based on simplified descriptions of the mass flux and heat release rate from the surface of a material. An alternative approach that avoids these simplifications has been implemented by Kulkarni and Fischer [10]. It utilizes the model of Reference 9 which has essentially the same physical assumptions as Eqn. (4) but does not assume a functional form for the mass loss rate from the sample; it does, however, still assume that the heat of combustion is a constant, as was done in the preceding analysis. The mass loss rate function for a unit area of the sample is obtained empirically from an apparatus intended to simulate the actual heat flux exposure seen by a typical area element of the sample surface during the flame spread process (item 2 under Upward Flame Spread in Table 1). A segment of the material of interest is mounted flush with a surrounding inert wall material. A flame from a gas burner impinges on the surface of this assembly simulating the flame from lower elements of burning material which would exist if a flame was spreading up a vertical surface composed only of the test material. The weight of the assembly is recorded as the flame gasifies the test sample and from this one infers the mass loss rate function needed by the model. The result is in numerical form; this creates no additional difficulties since the model calls for a numerical integration of its basic equations to obtain results such as flame spread rate or the extent of upward spread when continued spread is not possible.

While this approach to the prediction of upward flame spread behavior makes fewer assumptions than those implicit in Eqn. (4), it still does simplify reality. As presently implemented, this approach assumes that all elements of a vertical surface follow the same mass loss function. In reality there is a tendency for the heat flux to the surface to increase with scale as the flame becomes thicker and radiates more of its heat release back to the sample 
surface. This effect has not been extensively studied or characterized at this time. The mass loss function may also vary with the differing thermal profiles in the sample which result from differing preheat histories along the height of the sample; work in this area is just getting underway. A complete prediction scheme for vertical flame spread behavior thus does not exist at this time.

In view of these uncertainties, a third element in the area of vertical flame spread involves testing an essentialiy full-scale flat vertical surface of the same sample assembly as is tested in the two previous set-ups. The purpose is to test the accuracy of the predictions made, as described above, on the basis of bench-scale parameter inputs. In so doing, it complements the preceding tests rather than supersedes them. It is better to have a proven approach to predicting a wide potential range of full-scale behavior than it is simply to resort to a limited number of full-scale test scenarios to assess the flame spread behavior of a material.

\section{3) Concluding remarks}

The preceding discussion has summarized a systematic approach to assessing the elements of flammability pertinent to vertical flat surfaces of composite materials. The chief advantage of this approach is that it offers a way to project the bench-scale test results to new contexts. Application of this approach to non-charring and charring materials (including some composites) has met with a good degree of success $[9,10,11]$. There are certain issues in need of further study, however. As was noted in the preceding discussion, the flammability behavior of the edge regions of composite panels may be different than regions well away from edges. One can expect that the degree of difference may vary with the manner in which the edges are physically clamped, since this can affect the relative ease of escape of fuel gases from the face of a composite panel versus the edges. To the extent that these effects are related to delamination of the composite structure, one can also expect such factors as mechanical loading on the panel to play a role as well. These edge effects are normally present in the tests as now run. They typically are most noticeable at lower incident heat fluxes. A systematic study of their influence is lacking at this point, however. Plans are underway to examine their effects on ignitability and lateral flame spread in the near future. Another pertinent aspect of composite flammability in the context of Navy shipboard use is that of burnthrough or flame penetration of the composite assembly. Observations on this can be readily included in the tests summarized in Table 1; however, it appears that a more detailed examination of this issue may be needed. Finally, it should be noted that by characterizing the flammability of a composite in the manner discussed above one has gained a great deal of information useful in predicting its fire performance. However, one has not obtained sufficient information as to how to alter the composite formulation so as to improve flammability performance. One can envision a complementary program to that described here aimed at closing the gap in our understanding of how composite formulation influences composite flammability; such a program could help point the way to improved flammability behavior. 


\section{REFERENCES}

1) Quintiere, J., "A Perspective on Compartment Fire Growth", Combustion Science and Technology $39,(1984)$, p. 11

2) Quintiere, J., "The Application of Flame Spread Theory to Predict Material Performance", Journal of Research of the National Bureau of Standards 93 , $(1988)$, p. 61

3) Babrauskas, V. and Parker, W., "Ignitability Measurements with the Cone Calorimeter", Fire and Materials 11, (1987), p. 31

4) Babrauskas, V. and Wickstrom, U., "The Rational Development of Bench-Scale Fire Tests for Full-Scale Fire Prediction", paper presented at the Second International IAFSS Meeting, Tokyo, Japan, 1988

5) Quintiere, J., "Some Factors Influencing Fire Spread over Room Linings and in the ASTM E-84 Tunnel Test", Fire and Materials 9, (1985), p. 65

6) Wickstrom, U. and Goransson, U., "Prediction of Heat Release Rates of Surface Materials in Large-Scale Fire Tests Based on Cone Calorimeter Results", ASTM Journal of Testing and Evaluation 15, (1987), p. 364

7) Mitler, H., "Algorithm for the Mass-Loss Rate of Burning Wall", National Bureau of Standards NBSIR 87-3682, December, 1987

8) Quintiere, J., Harkleroad, M. and Walton, D., "Measurement of Material Flame Spread Properties", Combustion Science and Technology 32, (1983), p. 67

9) Saito, K., Williams, F. and Quintiere, J., "Upward Turbulent Flame Spread", Proceedings of the First IAFSS International Symposium, Hemisphere Publishing Co., New York, (1986), p. 75

10) Kulkarni, A. and Fischer, S., "A Model for Upward Turbulent Flame Spread on a Vertical Wall", Abstract for Fall Meeting of the Eastern States Section of the Combustion Institute, Clearwater, Florida, November, 1988

11) Harkleroad, M., "Ignition and Flame Spread Measurements of Aircraft Lining Materials", National Bureau of Standards NBSIR 88-3773, May, 1988

12) Atreya, A., Carpentier, C. and Harkleroad, M., "Effect of Sample Orientation on Piloted Ignition and Flame Spread", Proceedings of the First IAFSS International Symposium, Hemisphere Publishing Co., New York, $(1986)$, P. 97

13) Quintiere, J. and Harkleroad, M., "New Concepts in Measuring Flame Spread Properties", Fire Safety: Science and Engineering, ASTM STP 882, T. Z. Harmathy, ed. American Society for Testing Materials, Philadelphia, PA (1985), p. 239 

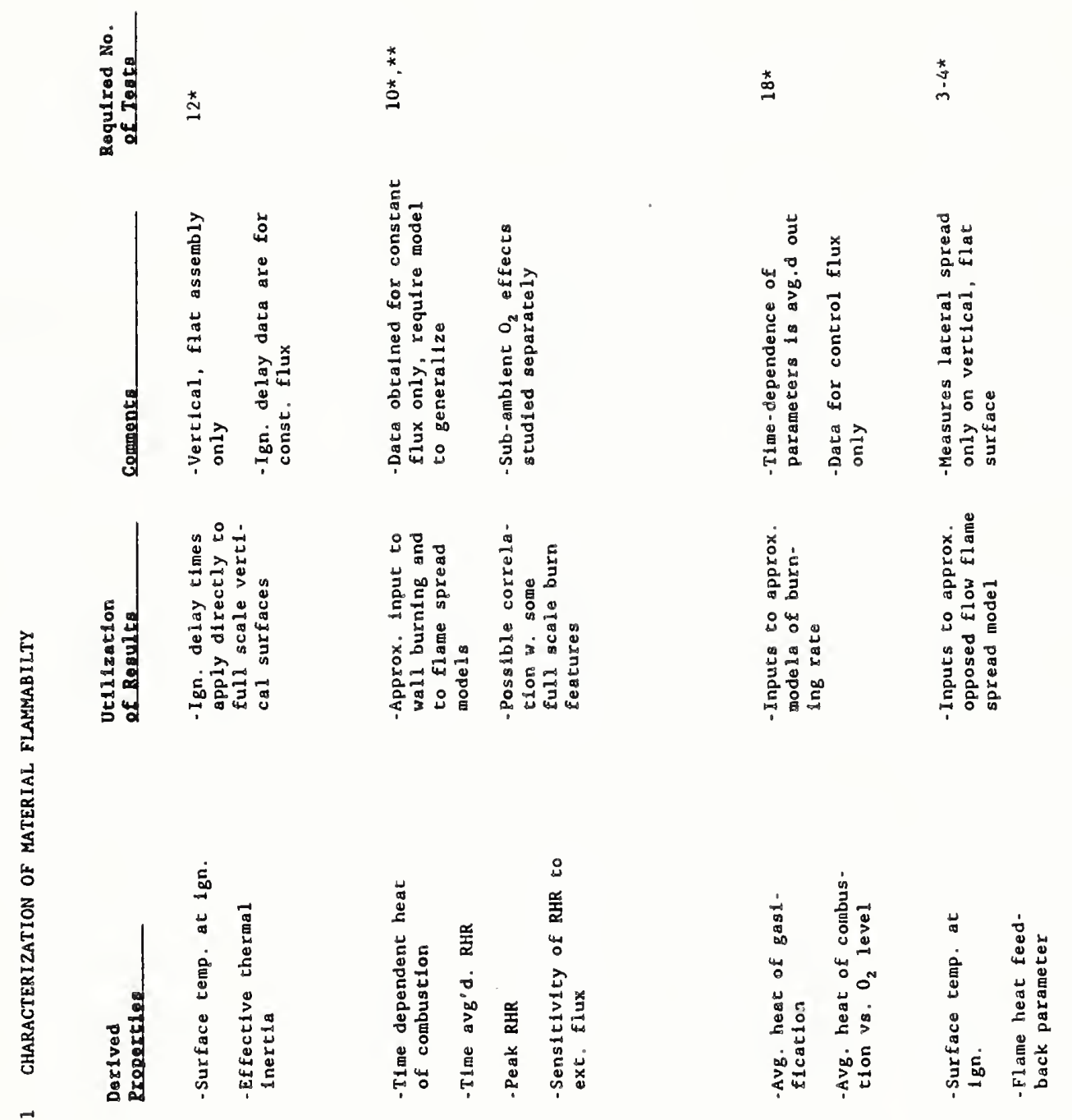

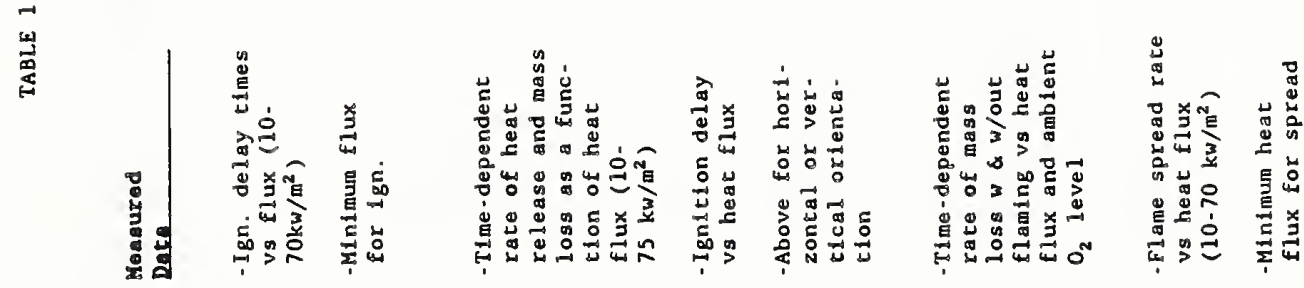

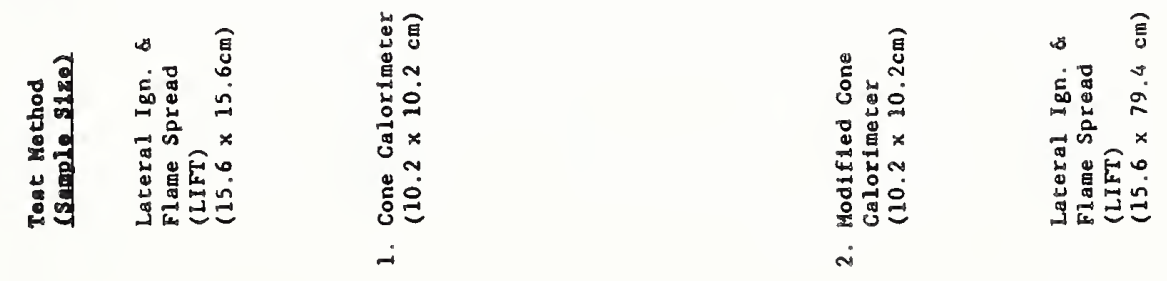
量

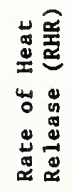

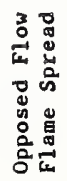



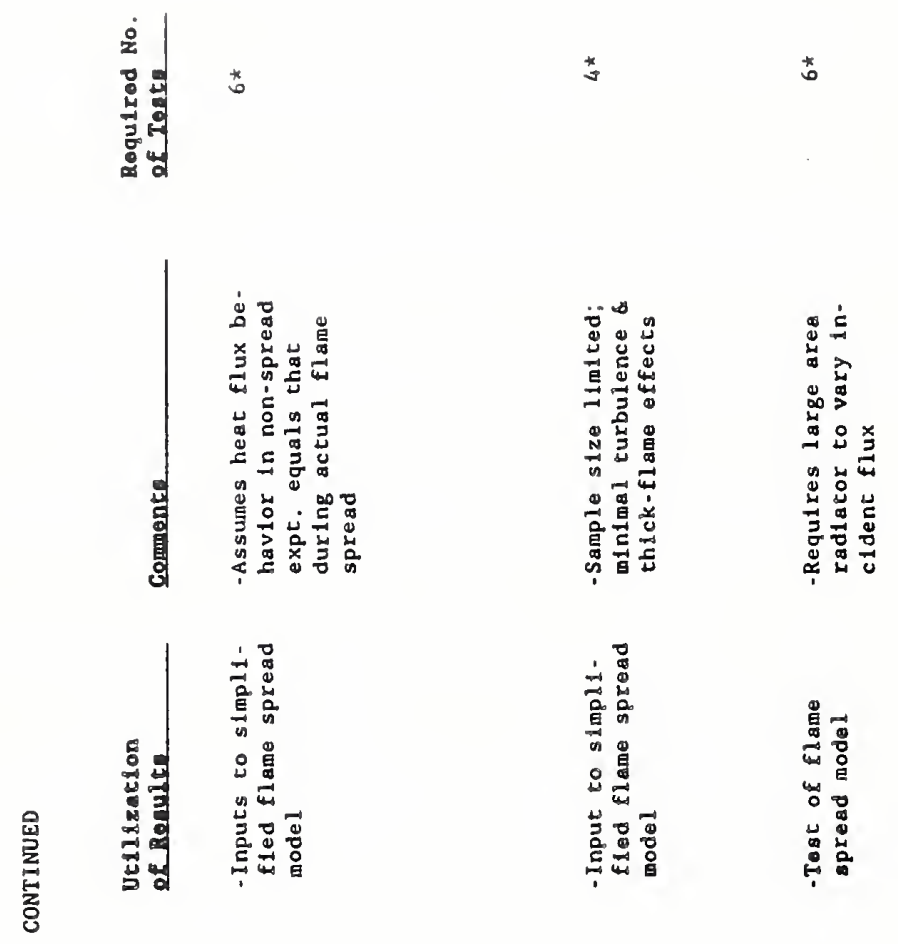

高

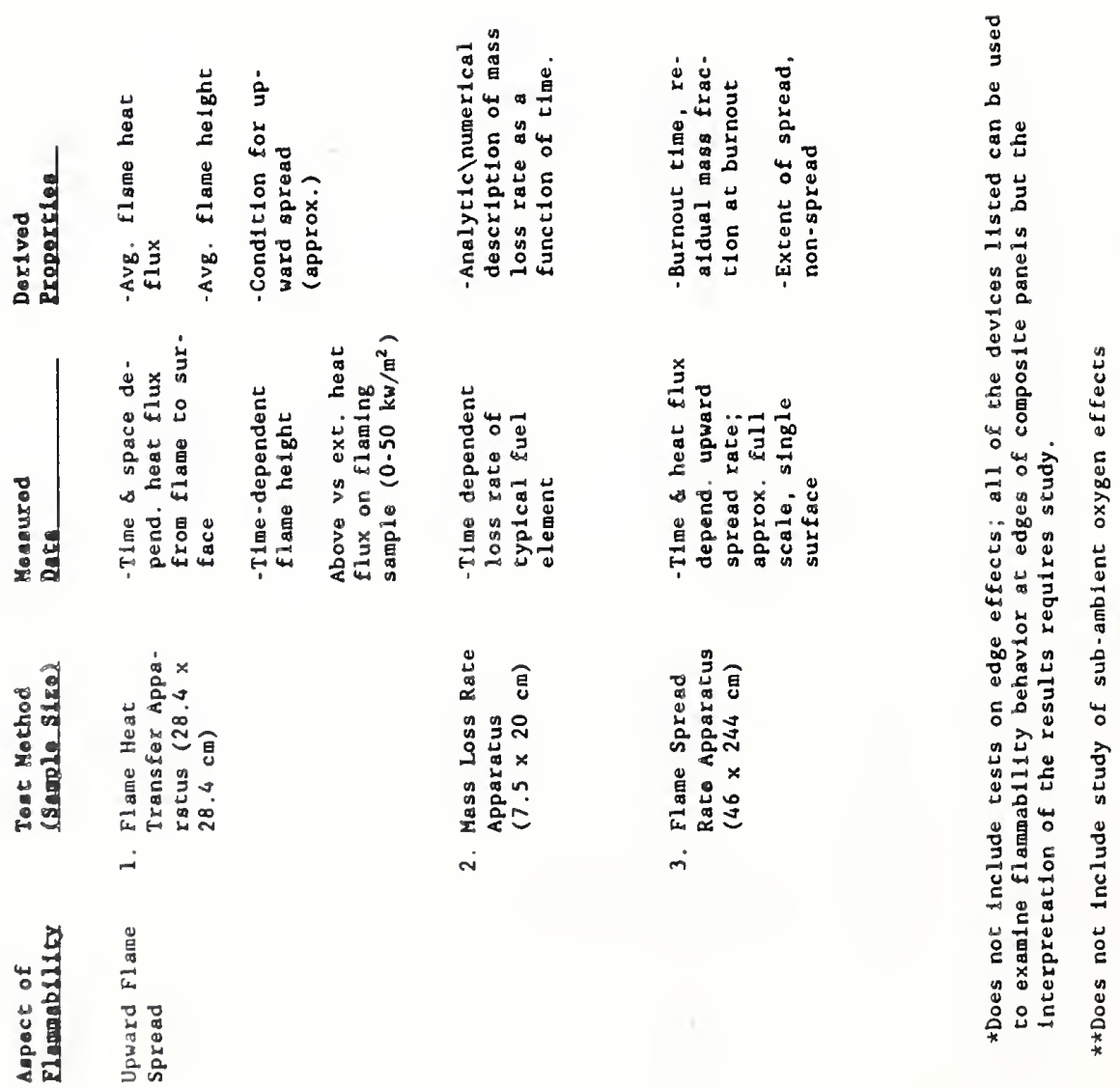




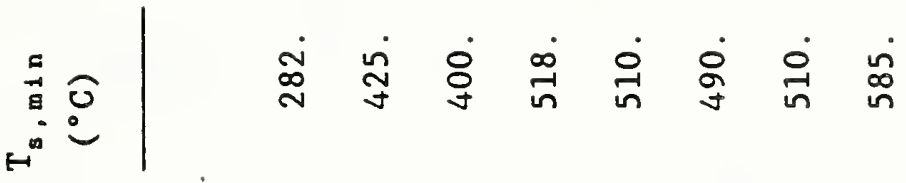

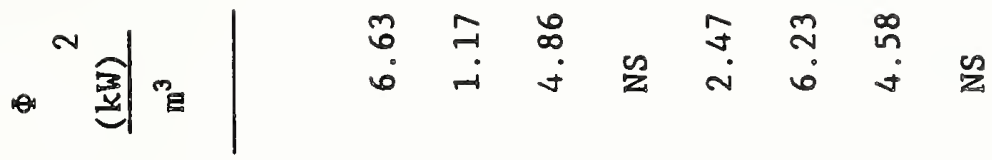

芯

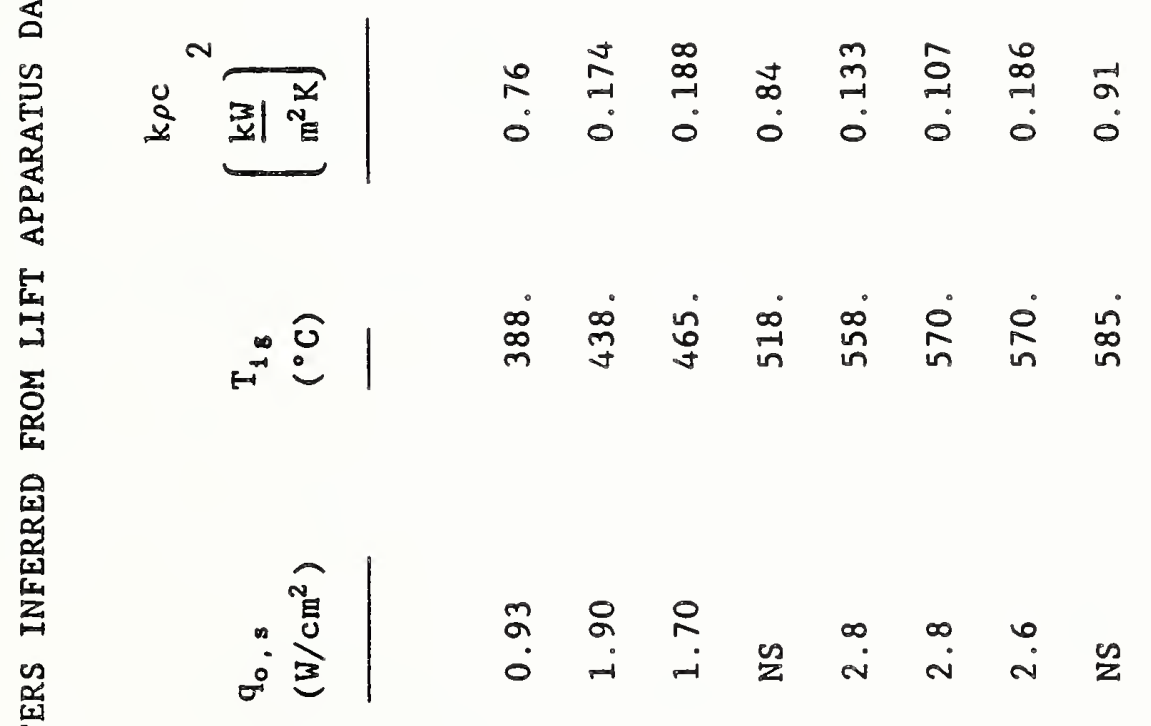

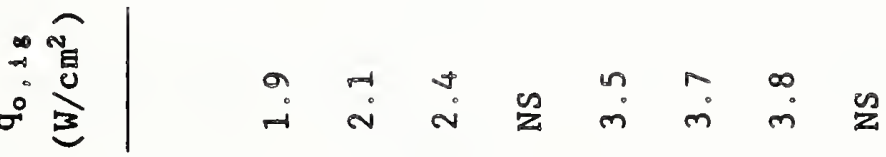

논

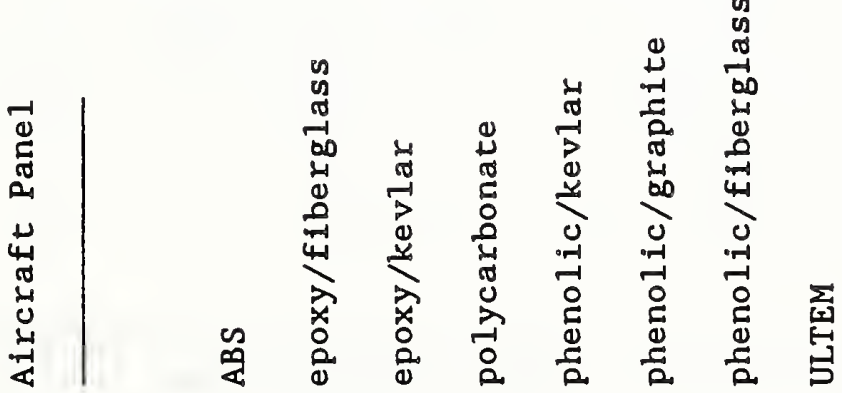




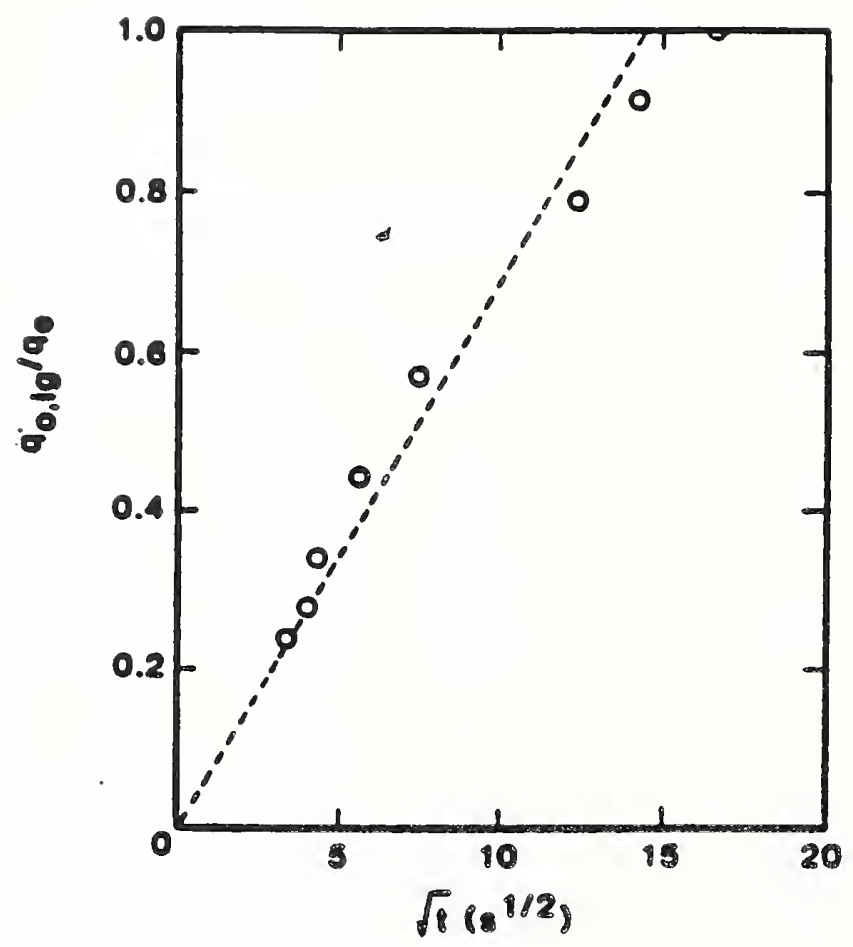

Fig. 1 Ignition data for fiberboard correlated by Eqn. (2)

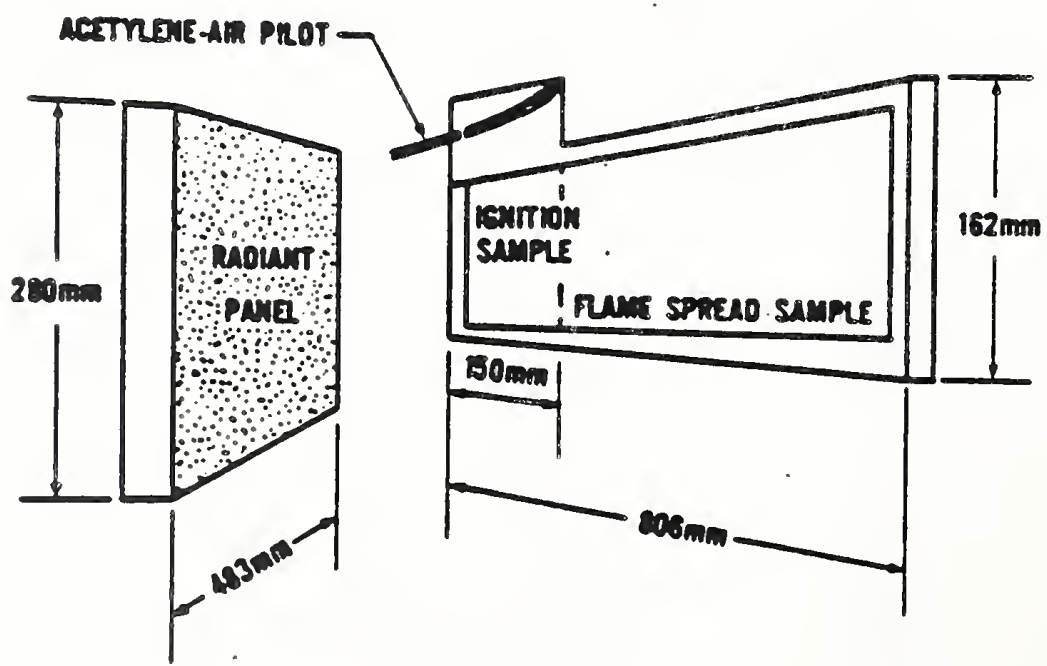

Fig. 2 Schematic of Lateral Ignition and Flame spread (IIFT) apparatus 


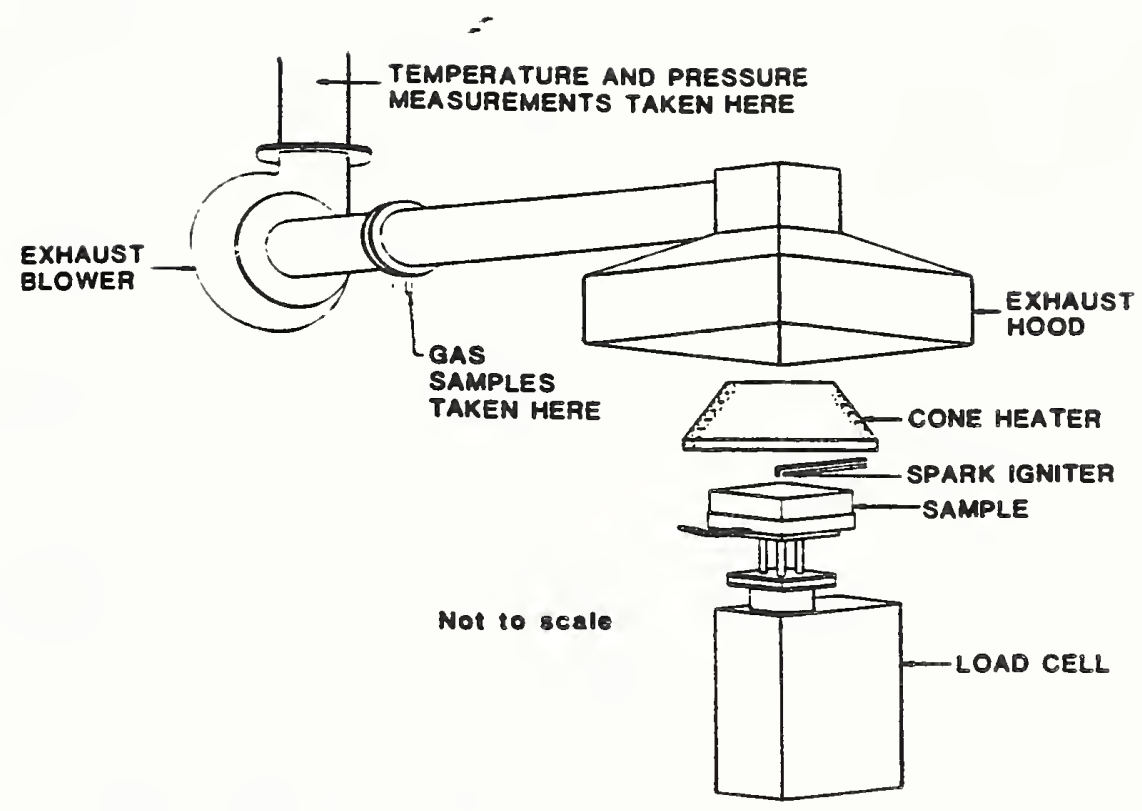

Fig. 3 Schematic of Cone Calorimeter for measurement of rate of heat release

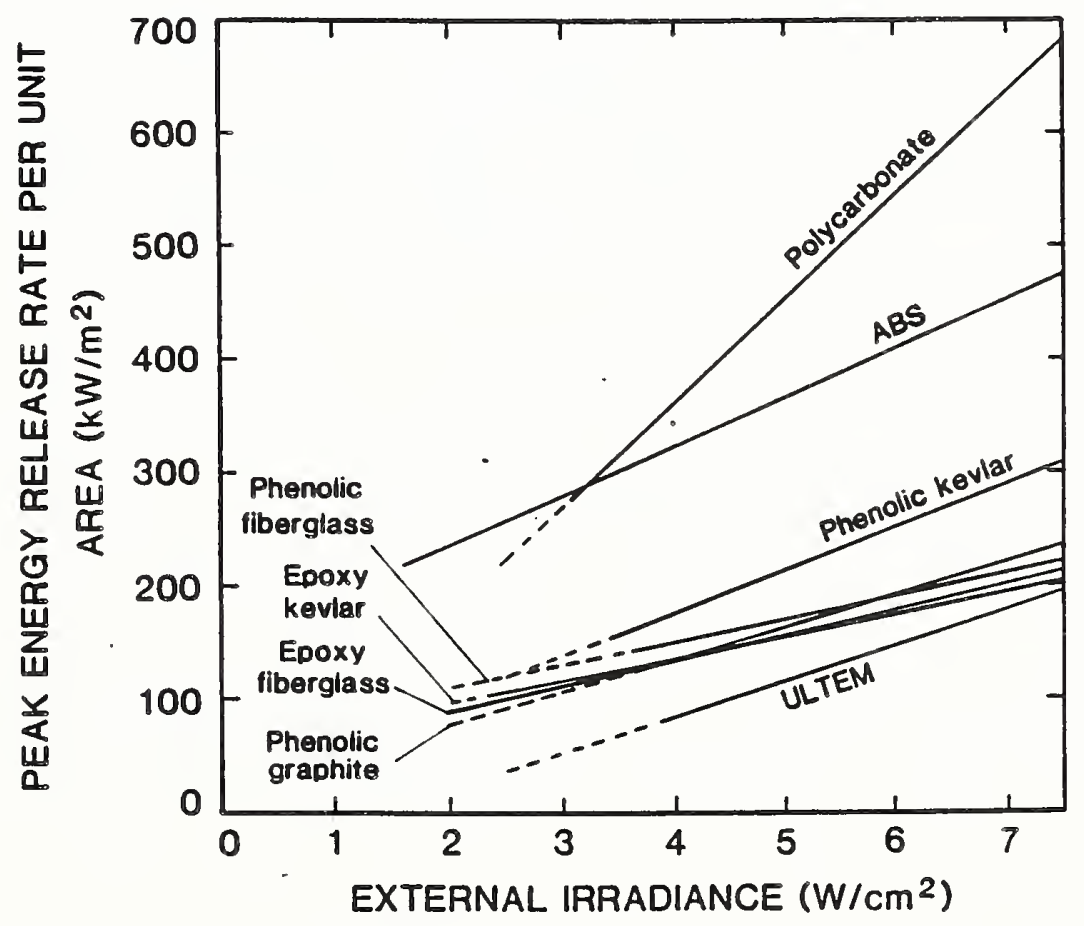

Fig. 4 Dependence of peak rate of heat release on incident heat flux; candidate materials for aircraft interior panels. 


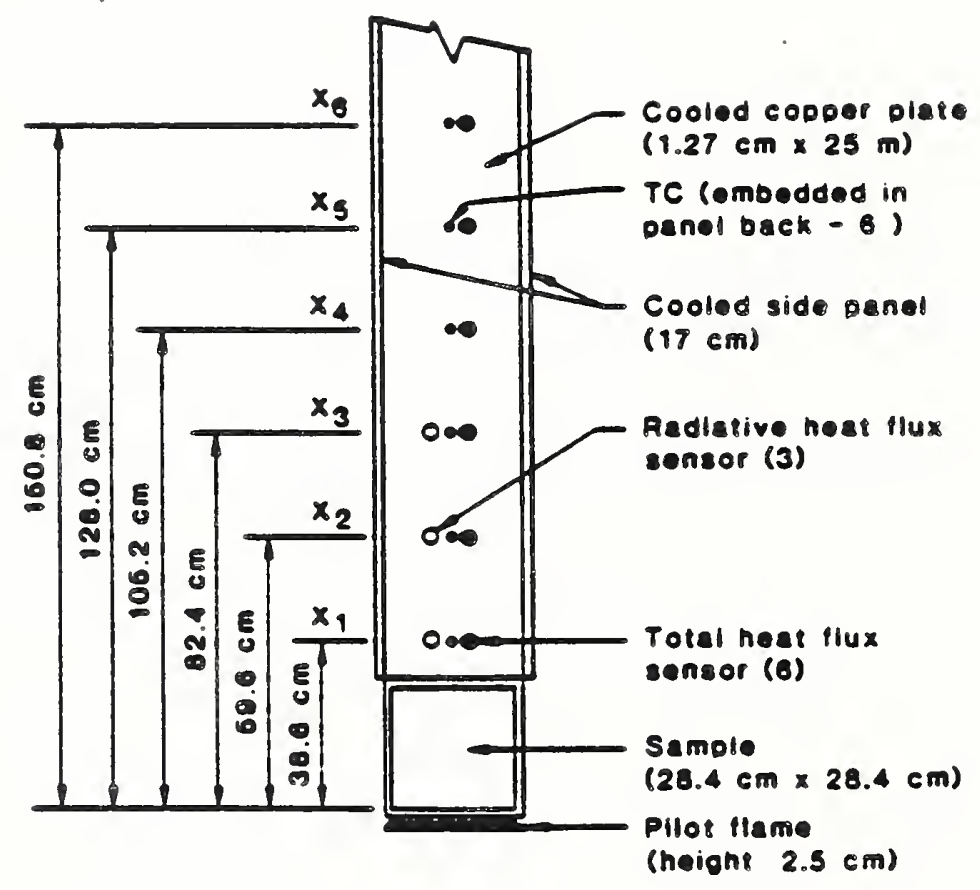

Fig. 5 Schematic of apparatus for measuring the heat flux from a flame to the surface of a marerial above the flame. 
NBS-1TAA IREV. 2-BC)

\begin{tabular}{|c|c|c|c|c|}
\hline $\begin{array}{r}\text { U.S. DEPT. OF COMM. } \\
\text { BIBLIOGRAPHIC DATA } \\
\text { SHEET (See instructions) }\end{array}$ & $\begin{array}{c}\text { 1. PUBLICATION OR } \\
\text { REPORT NO, Performing Organ. Report No } \\
\text { NISTIR-88/4032 }\end{array}$ & $\begin{array}{l}\text { 3. Publication Date } \\
\text { January }\end{array}$ & \begin{tabular}{l}
1989 \\
\hline
\end{tabular}
\end{tabular}

4. TITLE AND SUBTITLE

Assessing the Flammability of Composite Materials

5. AUTHOR(S)

Thomas J. Ohlemiller

6. PERFORMING ORGANIZATION (If joint or other than NBS, see instructions)

National Institute of Standards

and Technology

U.S. Department of Commerce

Gai thersburg, MD 20899

9. SPONSORING CRGANIZATION NAME AND CCMPLETE ADDRESS (Street. City. StOte, ZIP)

David Taylor Research Center

U.S. Navy

Annapolis, MD

10. SUPPLEMENTARY NOTES

Document describes a computer program: SF-185, FIPS Software Summary, is attached.

11. ABSTRACT (A 200-word or less foctual summary of most significant informazion. If document includes a significane bibliography or literature survey, mention it here)

A comprehensive approach to properly characterizing the flammability of composite materials is outlined. Laboratory-scale tests are described which provide measures of material ignitability, flame spread rate and heat release rate. Rather than expressing these measures as arbitrary indices, they are interpreted in terms of models of the controlling phenomena designed to provide information that can be generalized to full scale contexts, particularly compartment fires.

12. KEY WORDS (Six to twelve entries; alphabetical order; capitalize only proper names: and separate key words by semicolons) composite materials; flame spread; flammability; ignitability; polymers; rate of heat release

13. AVAILABILITY

EXI Unlimited

F For Official Distribution. Do Not Release to NTIS

Order From Superintendent of Documents, U.S. Government Printing Office, Washington. D.C. 20402.

X Order From National Technical Information Service (NTIS), Springfield, VA. 22161

14. NO. OF PRINTED PAGES

26

15. Price

$\$ 11.95$ 


